\title{
Cognitive Reserve: Implications for Assessment and Intervention
}

\author{
Yaakov Stern \\ Cognitive Neuroscience Division, Department of Neurology, and Taub Institute for Research in Alzheimer's Disease \\ and the Aging Brain, Columbia University College of Physicians and Surgeons, New York, N.Y., USA
}

\begin{abstract}
The concept of reserve is used to explain the observation that some individuals function better than others in the presence of brain pathology. This article reviews the concept of reserve from its theoretical basis to the implication of reserve for clinical practice. A distinction between brain reserve, referring to individual differences in the anatomic substrate, and cognitive reserve, referring to differences in the flexibility or adaptivity of cognitive networks, is useful. Epidemiologic evidence indicates that a set of life exposures including higher educational and occupational attainment, and engaging in leisure activities is associated with a lower risk of incident dementia, suggesting that these life exposures may enhance cognitive reserve. This provides a basis for controlled clinical studies that can test specific exposures that may enhance reserve. The concept of cognitive reserve also has important implications for clinical practice in terms of diagnosis and prognosis.

๑) 2013 S. Karger AG, Basel
\end{abstract}

\section{Introduction}

The concept of reserve is used to explain the observation that some individuals function better than others in the presence of brain pathology. In one study, the brains of 10 cognitively normal elderly women were found to have Alzheimer's plaques at autopsy [1]. It was observed that these women's brains were heavier in comparison to brains of normal elderly women in their database. The authors suggested that this provided 'reserve' which helped the women to function despite their pathology. Later studies have suggested that specific life experiences are associated with reduced risk of developing Alzheimer's disease (AD), and it has been suggested that these life experiences may also impart reserve against the effects of developing AD pathology. These initial observations led to the concepts of brain and cognitive reserve (CR). In this brief review, the theoretical basis for the concepts of brain and CR are discussed. Epidemiologic evidence for the contribution of life exposures to reserve is reviewed. The use of studies to explore the neural substrates underlying CR is described. Finally, studies intending to enhance reserve, and the implications of the concept of reserve for clinical practice are reviewed.

\section{Brain and CR}

These two observations are examples of two types of reserve: brain reserve and CR. In the original formulations of the brain reserve model, reserve derives from brain size or neuronal count. Larger brains can sustain more insult before clinical deficit emerges, because sufficient neural substrate remains to support normal function. In one formulation of this concept [2], there is a threshold of remaining brain reserve at which functional deficits will emerge. Thus, individuals with more brain

\section{KARGER}

E-Mail karger@karger.com

www.karger.com/fpl
(C) 2013 S. Karger AG, Basel

1021-7762/13/0652-0049\$38.00/0
Yaakov Stern, $\mathrm{PhD}$

Columbia University

630 West 168th Street, P \& S Box 16

New York, NY 10032 (USA)

E-Mail ys11@ columbia.edu 
reserve can accumulate more pathology before reaching that threshold. I suggested that this initial brain reserve model be termed a passive model in that it is entirely quantitative: a given brain injury affects each individual in the same manner and brain injuries throughout the lifespan sum together [3].

In contrast, CR refers to the ability to make flexible and efficient use of cognitive networks when performing tasks in the presence of brain pathology [3]. Thus, two people with the same level of brain reserve can appear different because one can make better use of the remaining brain substrate than the other. For this reason, those with higher CR tend to have better clinical outcomes for any level of pathology and brain reserve.

Although the initial conception of brain reserve was entirely quantitative, recent evidence suggests that this concept is more nuanced, in that the brain substrate can actually be altered by experience. For example, in animals stimulating environments foster the growth of new neurons in the form of neurogenesis [4-6], and up-regulate brain-derived neurotrophic factor, which is associated with enhanced neural plasticity. In addition exercise and life experience can be associated with changes in brain volume. Still, both brain reserve and CR can make independent contributions to understanding individual differences in clinical resilience to brain pathology.

This article reviews CR in the context of AD and normal aging, but it has also been demonstrated to provide benefit in vascular injury [7-9], Parkinson's disease [10], traumatic brain injury [11], HIV [12], neuropsychiatric disorders [13], and multiple sclerosis [14].

\section{Epidemiology of CR}

In 1994, my group reported incident dementia data from a follow-up study of 593 community-based, nondemented individuals aged 60 years or older [15]. After 1-4 years of follow-up, the risk of dementia was twice as high in subjects with low education (below 8 years) compared to those with higher education [relative risk, $2.2 ; 95 \%$ confidence interval (CI), 1.33-3.06]. The risk of incident dementia was also higher in those with low lifetime occupational attainment (relative risk, 2.25; 95\% CI, 1.32-3.84). We hypothesized that educational and occupational attainment reflect lifetime exposures that increase reserve against the expression of $\mathrm{AD}$ pathology. In a later study, we assessed participation in a variety of leisure activities [16]. During follow-up, subjects who engaged in more of these activities had $38 \%$ less risk of developing dementia.
Several studies have tested for a relationship between bilingualism and dementia. A retrospective chart review study of 184 patients from a memory clinic in Toronto reported that bilinguals were diagnosed with dementia an average of 4 years later than monolinguals [17]. Another retrospective study did not replicate this finding but noted a small protective effect of speaking three or more languages [18]. A study in a small sample of Hispanics with probable $\mathrm{AD}$ reported an association between bilingualism and later age of dementia diagnosis only among those patients with low education ( $\leq 11$ years) [19]. In all three of these studies, age of onset was not directly observed but was estimated from clinical history. In a study submitted for publication, our group examined the potential protective effect of bilingualism in a community-based study of initially nondemented Hispanic immigrants. The 1,238 elders were followed at 18- to 24-month intervals for up to 23 years. Spanish-English bilingualism was estimated via both self-report and an objective measure of English reading level. Bilingualism was associated with better memory and executive function at baseline. However, bilingualism was not independently associated with rates of cognitive decline or dementia conversion.

A review article [20] found 22 studies of the protective effects of education, occupation, premorbid IQ and mental activities on incident dementia. The great majority demonstrated significant protective effects. Overall, the authors reported that these life exposures were associated with significantly lowered risk for incident dementia (odds ratio, 0.54; 95\% CI, 0.49-0.59).

Epidemiologic evidence for CR can also be noted in studies of age-related cognitive decline. Several studies have found that higher educational attainment or literacy was associated with slower cognitive or functional decline [21-29].

\section{Neuroimaging Studies of CR}

The first imaging study of CR was designed to test the hypothesis that at any given level of clinical AD severity an individual with a higher level of CR should have greater AD pathology. Resting regional cerebral blood flow ( $\mathrm{rCBF}$ ) served as a surrogate for $\mathrm{AD}$ pathology, because specific $\mathrm{rCBF}$ changes in $\mathrm{AD}$ are related to the underlying $\mathrm{AD}$ pathology and $\mathrm{rCBF}$ becomes lower as the pathology advances [30, 31]. When $\mathrm{AD}$ patients were matched for clinical severity based on measures of cognition and function, there was a negative correlation between resting $\mathrm{rCBF}$ in the parietotemporal area affected 
in $\mathrm{AD}$ and years of education [32]: higher education was associated with more depleted flow. This suggests that patients with higher education were tolerating more $\mathrm{AD}$ pathology than those with lower education even though they were clinically similar. Many years later, this observation was confirmed in a prospective clinical study where deceased subjects' brains were subjected to postmortem neuropathological evaluation. Education was found to modify the association between $\mathrm{AD}$ pathology assessed post mortem and levels of cognitive function proximate to death: for the same degree of brain pathology there was better cognitive function with each year of education [33].

\section{Neural Mechanisms Underlying CR}

I have suggested that the neural implementation of CR might take two forms: neural reserve and neural compensation $[34,35]$. Neural reserve refers to the interindividual variability in the brain networks or cognitive paradigms that underlie the performance of any task in healthy individuals. This variability could be in the form of differing efficiency or capacity of these networks, or in greater flexibility in the networks that can be invoked to perform a task. An individual with greater neural reserve might be more capable of coping with the disruption imposed by brain pathology.

Neural compensation refers to the use of brain structures or networks not normally used by individuals with intact brains in order to compensate for brain damage. In some cases the greater use of the alternate network may be associated with better performance in the face of brain pathology. This type of compensation might represent the recruitment of alternate solution strategies to cope better with brain pathology. It is also possible that the use of compensatory networks may result in poorer performance. This could occur if brain pathology impacted on the typical network underlying performance. This could result in the recruitment of an alternate network that supports performance, but in a suboptimal way. A simple analogy is the use of a cane, which allows an elder to walk but not as well as if he did not need it. There are several reviews of my group's efforts to explore these ideas using imaging studies $[35,36]$.

\section{Implications of CR for Remediation and Prevention}

The epidemiologic evidence suggests that many exposures over the life course are associated with increased reserve against age-related or disease-related pathology.
Further, the evidence suggests that experiences at all stages of life, even in late life, can impart such reserve. These findings support the possibility that it may be possible to intervene even later in life in order to impart reserve, slow age-related cognitive decline, and prolong healthy aging. These observations are in line with the increasing realization of the plasticity of the aging brain and the fact that cognitive intervention might be useful in aging and dementia. The key difference between the general perspective towards cognitive intervention and my point of view is that my goal would be to increase reserve, rather than enhance any particular cognitive function.

The most successful remediation approach to date has been aerobic exercise. Many controlled studies in elderly individuals have demonstrated that, in individuals with below-median respiratory capacity, aerobic exercise that increases this respiratory capacity also results in increases in cognitive performance [37]. The results of cognitive intervention studies have been more mixed. One of the largest such studies was the ACTIVE study, in which a large number of elders were trained using protocols aimed at improving one of three cognitive domains: speeded attention, memory, and reasoning ability [38]. Each of these training protocols yielded improved performance within their domain that persisted over a long period of time. However, there was no evidence that training in one domain generalized to performance in any of the other two domains. In addition, there is no convincing evidence that training resulted in any improvement in activities of daily living.

More promising have been studies that have immersed subjects in complex gameplay. For example, Basak et al. [39] had elders play a complex role-playing game 'Rise of Nations' for $23.5 \mathrm{~h}$ and demonstrated that gameplay was associated with improved performance on a wide range of cognitive tasks. Our group has been working with another complex game, 'Space Fortress', that was designed by human operations psychologists as a test bed for training approaches to teach young adults complex tasks [40]. In this game, the player must control a spaceship and circle around a space fortress. The fortress shoots missiles at the player ship, and the player must avoid these missiles and in turn attempt to shoot at and destroy the fortress. Several other features of the game occur at the same time including the appearance of friend or foe mines that the player must attempt to destroy and the appearance of markers that are signals that the player can make a specific response to get bonus points. Each individual game lasts $3 \mathrm{~min}$ and participants typically play 12 games in a single session. In re- 
search with young adults, one particular training approach produced excellent improvement in gameplay, but, more importantly, also showed transfer of training to other tasks. In this approach, which is called emphasis change training, players are instructed to focus on all of the features of the game, but to give specific emphasis to one particular feature, either ship control or mine handling, during each individual game. By shifting emphasis from game to game, participants cannot fall into a fixed strategy. They must develop the ability to deal with the entire task as a whole - skills that might be termed attentional allocation or executive control. Younger people who learn to play the game using this training approach were more able to incorporate new demands while playing the game [41]. In addition, they showed more successful performance on real-world tasks such as flight simulator or flight training performance [42, 43]. In a preliminary study with older adults, we explored the capacity of the elders to learn to play the game, and the possibility that gameplay might improve cognitive performance [44]. Ninety subjects were divided into three groups: a non-gameplay condition, gameplay without emphasis change training, and gameplay with emphasis change training. The two gameplay groups played the game 3 times a week for 12 weeks. Interestingly, although the game itself was very challenging for the elders, there were few dropouts and performance improved over time. Analysis of various features of gameplay indicated that elders and the pure gameplay condition were not as focused on the key goals of the game as the emphasis change group; they were more likely to respond to signals for bonus points as opposed to attempting to destroy the space fortress. In contrast, the elders in the emphasis change condition were more likely to focus on features central to the game, in particular they were eventually more successful at destroying the space fortress than elders and the other group. Our primary cognitive measures were five tasks that involve executive control. On one of these tasks, a test of working memory, the emphasis change group showed greater improvement from pre- to posttesting than the other two groups [45]. We consider this a promising finding, and are currently conducting a study which combines space fortress gameplay with aerobic exercise. By combining a cognitive intervention with aerobic exercise we are hoping for a synergistic effect. The aerobic exercise may in effect boost brain reserve, for example by improving plasticity via up-regulation of brain-derived neurotrophic factor. The cognitive intervention, in turn, may help increase CR by increasing the efficien- cy of the cognitive networks underlying executive control. This cognitive efficiency would be facilitated by the improved level of brain reserve.

More generally, the epidemiologic data clearly suggest that aspects of life experience can impart reserve against age- or disease-related pathology. However, the exact 'recipe' for helping to create this reserve is still unknown. The most meaningful endpoints for such an intervention would be slowed rate of cognitive decline in aging or reduced risk of developing AD. Studies using these endpoints will be very expensive and will have to be conducted over long periods of time. Most likely, these studies should use multiple intervention strategies including exercise, cognitive stimulation and social stimulation.

\section{CR in Clinical Practice}

It can be very helpful to consider CR when evaluating patients. By definition, individuals with high reserve can tolerate more age-related brain changes or disease pathology than individuals with low levels of reserve. More challenging tests with higher ceilings may better detect changes in individuals with very high levels of CR. Tests that are directly tailored to tap performance changes related to underlying pathology should have greater sensitivity in high-reserve individuals. However, clinicians must be aware that even the most sensitive measures can fail to detect cognitive change when pathology is present.

Biomarkers that detect brain changes, for example PET scans sensitive to amyloid plaque, can detect pathological changes even when there is no impairment on neuropsychological testing. Thus, neuroimaging can be an aid in clinical evaluation. Theoretically, the optimal characterization of any clinical syndrome would be a combination of the measured pathology and measured reserve. For example, in $\mathrm{AD}$ we can now measure some aspects of disease pathology including plaques and tangles, and CR can be characterized by proxy such as educational or occupational attainment, and IQ. However, integration of this concept into day-to-day practice is premature because the prognostic implications of the current pathologic measures are not fully established. Still, the availability of these biomarkers provides a fruitful avenue for research into CR.

CR should also be recognized as a factor that will influence rate of cognitive decline following diagnosis of $\mathrm{AD}$. The rate of decline is more rapid in $\mathrm{AD}$ patients with high 
reserve than those with low reserve $[46,47]$. We believe that this is because once an individual with high $\mathrm{CR}$ reaches the point where pathology begins to affect performance, the level of pathology is quite advanced. We theorize that at that point the remaining reserve is quickly overcome by advancing pathology, resulting in rapid decline. This observation has strong implications for the design of clinical drug trials in $\mathrm{AD}$ because they typically compare rate of decline in a treated and a placebo group. A mismatch in CR across the two groups could lead to differential rates of decline that have nothing to do with the medication under study.

Epidemiologic evidence clearly links a set of lifetime exposures to lower rates of dementia. This might encourage clinicians to recommend engaging in specific activities in order to prevent or delay dementia. However, intervention studies are needed to firmly establish causal links between life experiences, individual characteristics, and CR, and such studies are underway. Therefore, while recommending that patients engage in certain activities such as mental enrichment and physical fitness is likely not to be harmful and may in fact have numerous positive effects, clinicians should be careful not to present these activities as established treatments or fully proven preventative strategies against dementia.

The differentiation between brain and CR is important theoretically, but also can serve as a guide for future research into clinical interventions that enhance reserve. It will be important to understand how life activities such as exercise or cognitive stimulation influence the brain substrate itself, and differentiate this from how CR is en- hanced. The potential synergy referred to above of attempting to enhance both brain and CR simultaneously also has great promise.

\section{Conclusion}

The concept of CR is very useful for explaining the disjunction between the degree of brain pathology and the clinical manifestations of that pathology. Epidemiologic observations support the idea that sets of lifetime exposures and individual characteristics are associated with greater reserve against the clinical expression of brain changes or pathology. Functional imaging studies have great promise for helping us to understand the neural basis of CR. Such studies may suggest optimal targets for intervening to increase CR. CR has practical implications for the clinical evaluation of patients. Finally, controlled studies may suggest interventions that can enhance CR in order to maintain successful aging and slow the onset of dementia. While $\mathrm{CR}$ was discussed in the context of aging and dementia in this review, the same concepts are applicable to any other condition associated with brain pathology. Finally, the concept of CR provides a frame for generating powerful and empirically testable research ideas.

\section{Acknowledgment}

Financial support provided by National Institute on Aging (NIA) grant R01 AG026158.

\section{References}

1 Katzman R, Terry R, DeTeresa R, Brown T, Davies P, Fuld P, Renbing X, Peck A: Clinical, pathological, and neurochemical changes in dementia: a subgroup with preserved mental status and numerous neocortical plaques. Ann Neurol 1988;23:138-144.

- Satz P: Brain reserve capacity on symptom onset after brain injury: a formulation and review of evidence for threshold theory. Neuropsychology 1993;7:273-295.

-3 Stern Y: What is cognitive reserve? Theory and research application of the reserve concept. J Int Neuropsychol Soc 2002;8:448-460.

4 Brown J, Cooper-Kuhn CM, Kemperman G, van Praag H, Winkler J, Gage FH: Enriched environment and physical activity stimulate hippocampal but not olfactory bulb neurogenesis. Eur J Neurosci 2003;17:2042-2046.
5 van Praag H, Christie BR, Sejnowski TJ, Gage FH: Running enhances neurogenesis, learning, and long-term potentiation in mice. Proc Natl Acad Sci USA 1999;96:1342713431.

6 van Praag H, Kemperman G, Gage FH: Running increases cell proliferation and neurogenesis in the adult mouse dentate gyrus. Nature Neurosci 1999;2:266-270.

7 Elkins JS, Longstreth WT, Manolio TA, Newman AB, Bhadelia RA, Johnston SC: Education and the cognitive decline associated with MRI-defined brain infarct. Neurology 2006; 67:435-440.

8 Dufouil C, Alperovitch A, Tzourio C: Influence of education on the relationship between white matter lesions and cognition. Neurology 2003;60:831-836.
Dufouil C, Alperovitch A, Ducros V, Tzourio C: Homocysteine, white matter hyperintensities, and cognition in healthy elderly people. Ann Neurol 2003;53:214-221.

10 Glatt SL, Hubble JP, Lyons K, Paolo A, Troster AI, Hassanein RE, Koller WC: Risk factors for dementia in Parkinson's disease: effect of education. Neuroepidemiology 1996;15:20-25.

$\checkmark 11$ Kesler SR, Adams HF, Blasey CM, Bigler ED: Premorbid intellectual functioning, education, and brain size in traumatic brain injury: an investigation of the cognitive reserve hypothesis. Appl Neuropsychol 2003;10:153162.

12 Farinpour R, Miller EN, Satz P, Selnes OA, Cohen BA, Becker JT, Skolasky RL, Visscher BR: Psychosocial risk factors of HIV morbidity and mortality: findings from the Multicenter AIDS Cohort Study (MACS). J Clin Exp Neuropsychol 2003;25:654-670.
Cognitive Reserve: Implications for

Assessment and Intervention
Folia Phoniatr Logop 2013;65:49-54 DOI: $10.1159 / 000353443$ 
13 Barnett JH, Salmond CH, Jones PB, Sahakian BJ: Cognitive reserve in neuropsychiatry. Psychol Med 2006;36:1053-1064.

-14 Sumowski JF, Chiaravalloti N, Deluca J: Cognitive reserve protects against cognitive dysfunction in multiple sclerosis. J Clin Exp Neuropsychol 2009;31:913-926.

-15 Stern Y, Gurland B, Tatemichi TK, Tang MX, Wilder D, Mayeux R: Influence of education and occupation on the incidence of Alzheimer's disease. JAMA 1994;271:1004-1010.

-16 Scarmeas N, Levy G, Tang MX, Manly J, Stern $\mathrm{Y}$ : Influence of leisure activity on the incidence of Alzheimer's disease. Neurology 2001;57:2236-2242.

17 Bialystok E, Craik FI, Freedman M: Bilingualism as a protection against the onset of symptoms of dementia. Neuropsychologia 2007; 45:459-464.

18 Chertkow H, Whitehead V, Phillips N, Wolfson C, Atherton J, Bergman H: Multilingualism (but not always bilingualism) delays the onset of Alzheimer disease: evidence from a bilingual community. Alzheimer Dis Assoc Disord 2010;24:118-125.

19 Gollan TH, Salmon DP, Montoya RI, Galasko DR: Degree of bilingualism predicts age of diagnosis of Alzheimer's disease in low-education but not in highly educated Hispanics. Neuropsychologia 2011;49:3826-3830.

20 Valenzuela MJ, Sachdev P: Brain reserve and dementia: a systematic review. Psychol Med 2005;25:1-14.

21 Manly JJ, Touradji P, Tang MX, Stern Y: Literacy and memory decline among ethnically diverse elders. J Clin Exp Neuropsychol 2003; 5:680-690.

22 Albert SM, Teresi JA: Reading ability, education, and cognitive status assessment among older adults in Harlem, New York City. Am J Public Health 1999;89:95-97.

23 Butler SM, Ashford JW, Snowdon DA: Age, education, and changes in the Mini-Mental State Exam scores of older women: findings from the Nun Study. J Am Geriatr Soc 1996; 44:675-681.

24 Chodosh J, Reuben DB, Albert MS, Seeman TE: Predicting cognitive impairment in highfunctioning community-dwelling older persons: Macarthur studies of successful aging. J Am Geriatr Soc 2002;50:1051-1060.
Christensen H, Korten AE, Jorm AF, Henderson AS, Jacomb PA, Rodgers B, Mackinnon $\mathrm{AJ}$ : Education and decline in cognitive performance: compensatory but not protective. Int J Geriatr Psychiatry 1997;12:323-330.

26 Farmer ME, Kittner SJ, Rae DS, Bartko JJ, Regier DA: Education and change in cognitive function: the epidemiologic catchment area study. Ann Epidemiol 1995;5:1-7.

27 Snowdon DA, Ostwald SK, Kane RL: Education, survival and independence in elderly catholic sisters, 1936-1988. Am J Epidemiol 1989;130:999-1012.

28 Lyketsos CG, Chen L-S, Anthony JC: Cognitive decline in adulthood: an 11.5-year followup of the Baltimore Epidemiologic Catchment Area study. Am J Psychiatry 1999;156: 58-65.

29 Colsher PL, Wallace RB: Longitudinal application of cognitive function measures in a defined population of community-dwelling elders. Ann Epidemiol 1991;1:215-230.

30 Friedland RP, Brun A, Budinger TF: Pathological and positron emission tomographic correlations in Alzheimer's disease. Lancet 1985;1:228.

- 31 McGeer EG, Peppard RP, McGeer PL, et al: 18-Fluorodeoxyglucose positron emission tomography studies in presumed Alzheimer cases, including 13 serial scans. Can J Neurol Sci 1990;17:1-11.

32 Stern Y, Alexander GE, Prohovnik I, Mayeux $\mathrm{R}$ : Inverse relationship between education and parietotemporal perfusion deficit in Alzheimer's disease. Ann Neurol 1992;32:371375.

-33 Bennett DA, Wilson RS, Schneider JA, Evans DA, Mendes De Leon CF, Arnold SE, Barnes LL, Bienias JL: Education modifies the relation of ad pathology to level of cognitive function in older persons. Neurology 2003;60: 1909-1915.

- 34 Stern Y, Habeck C, Moeller J, Scarmeas N, Anderson KE, Hilton HJ, Flynn J, Sackeim H, Van Heertum R: Brain networks associated with cognitive reserve in healthy young and old adults. Cereb Cortex 2005;15:394-402.

35 Stern Y: Cognitive reserve. Neuropsychologia 2009;47:2015-2028.
36 Steffener J, Stern Y: Exploring the neural basis of cognitive reserve in aging. Biochim Biophys Acta 2012;1822:467-473.

37 Angevaren M, Aufdemkampe G, Verhaar H, Aleman A, Vanhees L: Physical activity and enhanced fitness to improve cognitive function in older people without known cognitive impairment. Cochrane Database Syst Rev 2008;3:CD005381.

38 Jobe JB, Smith DM, Ball K, Tennstedt SL, Marsiske M, Willis SL, Rebok GW, Morris JN, Helmers KF, Leveck MD, Kleinman K: ACTIVE: a cognitive intervention trial to promote independence in older adults. Control Clin Trials 2001;22:453-479.

- 39 Basak C, Boot WR, Voss MW, Kramer AF: Can training in a real-time strategy video game attenuate cognitive decline in older adults? Psychol Aging 2008;23:765-777.

40 Mane A, Donchin E: The Space Fortress game. Acta Psychol 1989;71:17-22.

-41 Fabiani M, Buckley J, Gratton G, Coles MGH, Donchin E: The training of complex task performance. Acta Psychol 1989;71:259-299.

42 Gopher D, Weil M, Bareket T: Transfer of skill from a computer game trainer to flight. Hum Factors 1994;36:387-405.

43 Gopher D, Weil M, Siegal D: Practice under changing priorities: an approach to the training of complex skills. Acta Psychol 1989;71: 147-177.

44 Blumen HM, Gopher D, Steinerman JR, Stern Y: Training cognitive control in older adults with the space fortress game: the role of training instructions and basic motor ability. Front Aging Neurosci 2010;2:145.

45 Stern Y, Blumen HM, Rich LW, Richards A, Herzberg G, Gopher D: Space Fortress game training and executive control in older adults: a pilot intervention. Neuropsychol Dev Cogn B Aging Neuropsychol Cogn 2011;18:653677.

46 Stern Y, Tang MX, Denaro J, Mayeux R: Increased risk of mortality in Alzheimer's disease patients with more advanced educational and occupational attainment. Ann Neurol 1995;37:590-595.

47 Stern Y, Albert S, Tang MX, Tsai WY: Rate of memory decline in $\mathrm{AD}$ is related to education and occupation: cognitive reserve? Neurology 1999;53:1942-1957. 